\title{
Neonatal pain and COMT Val158Met genotype in relation to serotonin transporter (SLC6A4) promoter methylation in very preterm children at school age
}

\author{
Cecil M. Y. Chau ${ }^{1}$, Manon Ranger ${ }^{1,2}$, Dian Sulistyoningrum ${ }^{2}$, Angela M. Devlin ${ }^{2,3}$, Tim F. Oberlander ${ }^{1,2}$ \\ and Ruth E. Grunau ${ }^{1,2 *}$
}

\author{
'Developmental Neurosciences and Child Health, Child and Family Research Institute, Vancouver, BC, Canada \\ ${ }^{2}$ Pediatrics, University of British Columbia, Vancouver, BC, Canada \\ ${ }^{3}$ Diabetes, Nutrition and Metabolism, Child and Family Research Institute, Vancouver, BC, Canada
}

\section{Edited by:}

Katharina A. Braun,

Otto-von-Guericke University,

Germany

\section{Reviewed by:}

Guillaume L. Poirier, University of Massachusetts Medical School, USA

Sara Morley-Fletcher, Centre

National de la Recherche

Scientifique-University Lille, France

*Correspondence:

Ruth E. Grunau, Developmental Neurosciences and Child Health, F605B, 4480 Oak Street, Vancouver, BC V6H 3V4, Canada

e-mail: rgrunau@cw.bc.ca
Children born very preterm are exposed to repeated neonatal procedures that induce pain and stress during hospitalization in the neonatal intensive care unit (NICU). The COMT Val158Met genotype is involved with pain sensitivity, and early life stress is implicated in altered expression of methylation of the serotonin transporter. We examined: (1) whether methylation of the serotonin transporter gene (SLC6A4) promoter differs between very preterm children and full-term controls at school age, (2) relationships with child behavior problems, and (3) whether the extent of neonatal pain exposure interacts with the COMT Val158Met genotype to predict SLC6A4 methylation at 7 years in the very preterm children. We examined the associations between the COMT genotypes, neonatal pain exposure (adjusted for neonatal clinical confounders), SLC6A4 methylation and behavior problems. Very preterm children had significantly higher methylation at 7/10 CpG sites in the SLC6A4 promoter compared to full-term controls at 7 years. Neonatal pain (adjusted for clinical confounders) was significantly associated with total child behavior problems on the Child Behavior Checklist (CBCL) questionnaire (adjusted for concurrent stressors and 5HTTLPR genotype) $(p=0.035)$. CBCL Total Problems was significantly associated with greater SLC6A4 methylation in very preterm children $(p=0.01)$. Neonatal pain (adjusted for clinical confounders) and COMT Met/Met genotype were associated with SLC6A4 promoter methylation in very preterm children at 7 years $(p=0.001)$. These findings provide evidence that both genetic predisposition and early environment need to be considered in understanding susceptibility for developing behavioral problems in this vulnerable population.

Keywords: preterm, epigenetic, serotonin transporter, catechol-O-methyltransferase, methylation, pain, child, premature

\section{INTRODUCTION}

Early life adversity and stress exposure are associated with alterations in DNA methylation and changes in gene expression (McGowan et al., 2009; Meaney, 2010; Bagot et al., 2012) and importantly, such changes may be already taking shape long before birth (Oberlander et al., 2008). DNA methylation is a critical epigenetic mechanism regulating gene expression and has been suggested as a possible molecular mechanism explaining the diversity in behavioral outcomes that follow exposure to early life stressful events (Caspi et al., 2003; Rutter et al., 2006; McGowan et al., 2009). DNA methylation offers a promising direction that enables us to understand how exposure to adverse/stressful early

Abbreviations: NICU, neonatal intensive care unit; HPA, hypothalamic-pituitaryadrenal axis; 5HTTLPR, serotonin-transporter-linked polymorphic region; $\mathrm{CPG}$, cystosine-guanosine dinucleotide pairs; DA, dopamine; COMT, catechol-Otransferase; PFC, prefrontal cortex; PCA, principal component analysis; GZLM, generalized linear modeling. life events may lead to enduring changes in neuronal function (Karsten and Baram, 2013).

Infants born very preterm [24-32 weeks gestational age (GA)] spend weeks to months in the neonatal intensive care unit (NICU) during a delicate and critical phase of very rapid brain development, and programming of stress systems (Grunau et al., 2004; Tu et al., 2007). In the NICU, these infants require numerous invasive medical procedures to diagnose and treat lifethreatening conditions. This environment contrasts greatly from the calm and protective maternal intrauterine environment, thus exposing these fragile neonates to repeated highly stressful and potentially painful experiences that are developmentally unexpected. Since stress and pain cannot be distinguished in immature neonates, we have used the term "pain-related stress." Despite major improvement in the care of very preterm infants, rates of neurodevelopmental problems in children born very preterm do not appear to have improved, affecting about $50 \%$ of survivors (Gray et al., 2004; Aarnoudse-Moens et al., 2009). There are 
concerns regarding long-term consequences of pain-related stress in very preterm neonates. Recent work from our group found that procedural pain/stress exposure (controlling for clinical factors related to prematurity, such as gestational age, postnatal infection, cumulative morphine dose, days of mechanical ventilation, illness severity on day 1, and number of surgeries) was associated with altered gray and white matter maturation (Brummelte et al., 2012; Ranger et al., 2013; Vinall et al., 2013a), corticospinal tract development (Zwicker et al., 2013a,b), poorer motor (Zwicker et al., 2013a), cognitive (Grunau et al., 2009; Doesburg et al., 2013), and behavioral functioning in very preterm children (Vinall et al., 2013b; Ranger et al., 2014). Moreover, greater cumulative exposure to neonatal pain/stress has been associated with altered developmental trajectory of stress hormone (cortisol) expression [i.e., programming of the hypothalamic-pituitary-adrenal axis (HPA)] long after NICU discharge (Grunau et al., 2007, 2013; Miller et al., 2011). Examining the role of gene and environment interactions is important to understand mechanisms and the etiology of how early pain/stress contributes to altered neurodevelopment in very preterm children.

We have taken a hypothesis-based targeted gene approach. Two key stress and mood regulatory neurotransmitters and related regulatory genes have been identified: serotonin and dopamine. Serotonin is a widely distributed neurotransmitter that appears early in gestation that plays a key role in early brain development and later emotion, attention, cognition, and learning during childhood (Lucki, 1998; Lesch, 2007; Weikum et al., 2013). Central to the regulation of intrasynaptic serotonin (5-hydroxytryptamine, 5HT) concentrations is the presynaptic membrane-bound serotonin transporter protein (5HTT, encoded by $S L C 6 A 4)$. Variants in the serotonin transporter promoter region (5HTTLPR), are associated with altered gene expression and 5HTT concentrations, and therefore have a critical role in determining intrasynaptic serotonin signaling (Hanley and Oberlander, 2012). The short (S) allele of 5HTTLPR results in $\sim 50 \%$ reduction in serotonin reuptake compared to the long $(\mathrm{L})$ allele (Heils et al., 1996). S allele carriers may have greater vulnerability for emotional disorders (Homberg and Lesch, 2011), particularly in the context of early life stress (Caspi et al., 2003) (recent reviews Serretti et al., 2007; Kuzelova et al., 2010). Manipulations of 5HT signaling, either via pharmacologic 5HTT blockade or SLC6A4 knock-out in mouse models, that increase serotonin concentrations during developmentally sensitive periods, are associated with lasting behavioral, neurophysiological, and neuroanatomical changes in animal models (Homberg et al., 2010; Olivier et al., 2011; Simpson et al., 2011) and increased risk for anxiety/depression symptoms in humans (Oberlander et al., 2010; Weikum et al., 2013). It is well established that behavioral problems such as attention deficit problems, internalizing (depressive/anxiety symptoms), and to some extent externalizing (aggressive, hyperactivity symptoms) behaviors are prevalent in children born very preterm (Bhutta et al., 2002; Gray et al., 2004; Aarnoudse-Moens et al., 2009). Recently, methylation of the SLC6A4 promoter was shown to be associated with early childhood adversity in adults with major depression (Kang et al., 2013). Therefore, examining the impact of early life stress on changes in the methylation of the SLC6A4 promoter in very preterm children is likely to add to our understanding of how early changes in serotonin signaling might be associated with altered neurodevelopmental outcomes differences previously reported in this population compared to term born counterparts.

Catechol-O-transferase (COMT) gene encodes for a key enzyme in the metabolism of dopamine (DA), norepinephrine (NE), and epinephrine (EPI) (Lotta et al., 1995). The Met/Met genotype of the COMT Val158Met variant is associated with more than a three- to four-fold decrease in COMT enzyme activity and DA catabolism, which leads to an increase in DA availability and reduced myelination (Lotta et al., 1995; Chen et al., 2004). This is especially significant in the prefrontal cortex (PFC) where COMT activity is the primary determinant of synaptic DA concentrations (Garris and Wightman, 1994; Karoum et al., 1994). COMT variants have been associated with cognitive functions (Blasi et al., 2005; Dumontheil et al., 2011); and mood disorders (Enoch et al., 2003; Olsson et al., 2007; Aberg et al., 2011). For example, individuals with the Met allele are at increased risk for anxiety (Enoch et al., 2003; Olsson et al., 2007).

Moreover, Zubieta and colleagues reported effects of the COMT Val158Met genotype on $\mu$-opioid system activation in young adults, where individuals with the Met/Met genotype had greater pain sensitivity and negative emotions to pain compared to individuals with the Met/Val and Val/Val genotypes (Zubieta et al., 2003). Further, the Val allele has been associated with increased risk of schizophrenia in both European and Asian populations (Fan et al., 2005), and decreased cognitive stability (Bialecka et al., 2008). COMT and 5HTT have important functional roles in regulating neurotransmission with mood and behavior brain-related pathways, and given that both have functional genetic variants, researchers have begun to investigate their potential interaction in various pathologies (Olsson et al., 2007; Radua et al., 2014).

Since both dopaminergic and serotonergic systems play a critical role in mood regulation, there has been a considerable amount of interest in their potential interactions. Drugs enhancing dopaminergic function such as buproprion are also effective antidepressants (Ascher et al., 1995). In rodents, exposure of the striatum and nucleus accumbens to serotonin increased dopamine release (review by Sasaki-Adams and Kelley, 2001). Dopamine and serotonin systems also showed a significant degree of convergence and plasticity in the rat medial prefrontal cortex (Benes et al., 2000).

To further understand how early life stress exposure may contribute to altered behavior in children born very preterm, this study was undertaken to determine if methylation of SLC6A4 promoter differed between very preterm children and full-term controls at age 7 years. We hypothesized that methylation at school age would be altered in those born very preterm due to the stressful neonatal environment. We further explored whether child behavioral problems, concurrent child stress level, and parental factors were associated with differences in methylation. To investigate the effects of neonatal stress on child behavioral problems and SLC6A4 methylation, in very preterm group only, we examined whether neonatal procedural pain exposure (adjusted for clinical confounders) and/or concurrent stressors are associated 
with child behavioral problems at age 7 years. Finally, in very preterm group only, we examined the effect of neonatal procedural pain exposure (adjusted for clinical confounders) and COMT Val158Met genotype on SLC6A4 methylation at 7 years. Given that COMT Val158Met genotype has been reported to be associated with cognitive functions and pain sensitivity, we hypothesized that the extent of early pain exposure would interact with the COMT Val158Met genotype to affect SLC6A4 methylation.

\section{MATERIALS AND METHODS PARTICIPANTS}

Participants were part of a larger longitudinal study of longterm effects of neonatal pain-related stress on brain, stress and neurodevelopment of children born very preterm (24-32 weeks gestation) (e.g., Grunau et al., 2007, 2009), who were admitted to the level III NICU at Children's and Women's Health Centre of British Columbia between 2000 and 2004. A total of 111 school age children, 61 born very preterm and 50 born full-terms were included in the current study [ 56 boys/55 girls; mean age $7.78 \mathrm{y}$ $( \pm 0.65)$ range 6.3-10.8 years]. Parents completed questionnaires while children were undergoing psychometric testing.

All of the children had an IQ score above 70 on the Wechsler Intelligence Scale for Children-4th Ed (Wechsler, 2003). None had major cognitive, sensory, motor impairments, or was diagnosed with autism. We included in our sample three very preterm children with intraventricular hemorrhage (IVH) grade 1 or 2, and two grade 3 or 4, on neonatal ultrasound. This study was approved by the Clinical Research Ethics Board of the University of British Columbia and the Research Ethics Board of the B.C. Children's and Women's Hospitals, and conforms to the conventions set out in the Declaration of Helsinki. Written informed consent was obtained from parents and assent from children.

\section{NEONATAL DATA}

Medical and nursing chart review of children born very preterm was carried out by an experienced neonatal research nurse. The data collection included but was not limited to, GA, birth weight, illness severity on day 1 [Score for Neonatal Acute Physiology (SNAP)- II (Richardson et al., 2001)], days of mechanical ventilation, presence of culture proven infection, number of surgeries, and cumulative dose of morphine (Table 2). We quantified neonatal pain-related stress as the number of skin-breaking procedures (e.g., heel lance, peripheral intravenous or central line insertion, chest-tube insertion, and nasogastric tube insertion) during the stay in the NICU, as previously reported (e.g., Grunau et al., 2009; Brummelte et al., 2012). Each attempt at a procedure was counted as one skin-break; all nursing staff in our NICU have been trained to precisely record each attempt. Cumulative morphine exposure was calculated as the average daily dose (i.e., intravenous dose plus intravenous-equivalent oral dose) adjusted for daily body weight, multiplied by the number of days morphine was administered.

\section{MEASURES/ASSESSMENTS}

Children completed the Wechsler Intelligence Scale for Children-Fourth Edition (WISC-IV) (Wechsler, 2003).
A parent (110 mothers, 1 father) completed the following questionnaires:

- Child Behavior Checklist (CBCL) for children ages 6-18 years (Achenbach and Rescorla, 2000), the most widely used questionnaire for identifying problem behaviors in children. Ratings are on a 3-point Likert scale [ranging from 0 (not true) to 2 (very true or often true)] on 113 items regarding child behavior in the past 6 months. The checklist is comprised of eight syndrome scales (Anxious/Depressed, Withdrawn/Depressed, Social Problems, Somatic Complaints, Thought Problems, Attention Problems, Aggressive Behavior, and Rule-Breaking Behavior) and two higher order-factors of Internalizing and Externalizing Problems. Raw scores were converted to age-standardized scores ( $T$ scores with mean $=50$ and $S D=10$ ) based on the normative samples of children for age range separately by sex (Achenbach and Rescorla, 2000). The Total Problems T-score was used as an indicator of overall emotional and behavioral problems of the child, and yields an alpha coefficient of 0.97 (Achenbach and Rescorla, 2000).

- The Beck Depression Inventory-2nd Editions (BDI-II) (Beck et al., 1961) a 21-item self-report multiple-choice questionnaire widely used to assess the presence and severity of symptoms of depression, was used to evaluate parent depression. The scale yields a single score that ranges from 0 to 63 , with higher scores indicating higher level of depression; reliability alpha coefficient 0.92 (Gatewood-Colwell et al., 1989).

- The State-Trait Anxiety Inventory (Spielberger et al., 1983) comprised of two separate 20-statement self-report scales: the State-Anxiety scale to evaluate how respondents feel "right now, at this moment" and the Trait-Anxiety scale how respondents generally feel. Only the Trait Anxiety Scale was used in the present study as an indicator of parent general anxiety symptoms. Scores range from 20 to 80 ; reliability alpha coefficient 0.86 (Spielberger et al., 1983).

\section{HAIR CORTISOL}

Cortisol was assayed from hair as an integrated measure of stress level (HPA activity) in the previous 2 months following our published protocol (Grunau et al., 2013; Vaghri et al., 2013). Hair samples were collected from the vertex posterior of the head, as this area has been shown to have the lowest coefficient of variation in hair cortisol concentrations (Sauve et al., 2007). A cluster of hair strands ( $\sim 2-3 \mathrm{~mm}$ diameter $)$ was cut at the base of the hair shaft from five small spots. The hair samples were secured on a cardboard card with tape, labeled, and stored in individual sealed plastic bags at room temperature until analysis. The most proximal $2 \mathrm{~cm}$ from the scalp of each hair sample was utilized for the assay. Ten to $15 \mathrm{mg}$ from each hair sample was placed in scintillation vials. To remove external contaminants, hair samples were washed twice by immersion in $3 \mathrm{~mL}$ of isopropanol and incubating at room temperature in a centrifuge at $100 \mathrm{rpm}$ for $3 \mathrm{~min}$. After decanting the isopropanol, samples were allowed to dry for at least $12 \mathrm{~h}$. After drying, $1 \mathrm{~mL}$ of methanol was added to each scintillation vial. Hair was then finely minced with surgical scissors. The vials were sealed with paraffin film and incubated for $16 \mathrm{~h}$ at $50^{\circ} \mathrm{C}$ in a centrifuge at $100 \mathrm{rpm}$. Following methanol 
extraction each cortisol-containing methanol solution was transferred into $5 \mathrm{~mL}$ test tubes and evaporated on a test tube hot plate under a steady stream of nitrogen gas. The residue was then reconstituted with $250 \mu \mathrm{L}$ of phosphate buffered saline. These reconstituted samples were analyzed using the salivary enzyme linked immunoassay kit (Alpco Diagnostics, Salem, NH, USA). The intra-assay and inter-day coefficients of variation were 8.9 and $5.1 \%$, respectively. The kit reported a sensitivity of $1.0 \mathrm{ng} / \mathrm{mL}$.

\section{GENOTYPING}

Genomic DNA was extracted from saliva using Oragene OG500 and prepIT-L2P collection kit (DNA Genotek/OraSure Technologies Inc., Bethlehem, Pennsylvania). The COMT Val158Met (rs4680) variant was genotyped using TaqMan SNP Genotyping Assay reagents and an Applied Biosystems 7300 Real Time PCR System (Applied Biosystems, Carlsbad, California). Call rate was $100 \%$. The Hardy-Weinberg equilibrium of allelic distribution of the cohort was examined and compared to the population distribution by chi-square test.

The $\mathrm{L}$ and $\mathrm{S}$ alleles of the $5 H T T L P R$ serotonin transporter variant was genotyped by polymerase chain reaction (PCR) with the following primers stpr5, 5'-GGCGTTGCCGCTCTGAATGC and stpr3, 5'-GAGGGACTGAGCTGGACAACCAC to generate a 484-bp (S short allele) or a 528-bp (L long allele) product, distinguished by agarose gel electrophoresis.

\section{EPIGENETIC ANALYSIS}

Using the DNA from saliva, the methylation status of a CpG-rich region in the $S L C 6 A 4$ promoter was quantified by bisulfite Pyrosequencing (Dupont et al., 2004) as previously described (Devlin et al., 2010). This region of the SLC6A4 promoter has been reported to be differentially methylated and associated with changes in SLC6A4 mRNA expression (Philibert et al., 2007, 2008; Devlin et al., 2010). Briefly, we have analyzed a region of the SLC6A4 promoter between -479 and -350 , relative to the transcriptional start site, which contains $10 \mathrm{CpG}$ sites and is adjacent to exon 1a (Devlin et al., 2010). Genomic DNA was bisulfite-treated using the EZ DNA Methylation Gold Kit (Zymo Research) following the manufacturer's instructions and stored at $-20^{\circ} \mathrm{C}$ until further analyzed. A $130 \mathrm{bp}$ fragment of the SLC6A4 promoter was amplified by PCR from bisulfitetreated DNA using HotStar Taq DNA Polymerase (Qiagen) and the following primers for SLC6A4: PMHSERTF, 5'-GTATTG TTAGGTTTTAGGAAGAAAGAGAGA-3' and PMHSERTR, 5'-AAAAATCCTAACTTTCCTACTCTTTAACTT-3' (IDT Inc, Coralville, IA), with the reverse primer containing a biotin at the $5^{\prime}$ end. PCR products were purified and sequenced using a PyroMark MD System (Biotage, Foxboro, MA) following the manufacturer's suggested protocol and the following sequencing primer PMHSERTS, 5'-AAACTACACAAAAAAACAAAT-3' (IDT). The percent methylation at each $\mathrm{CpG}$ site was quantified using the Pyro Q-CpG software, version 1.0.9 (Biotage).

\section{STATISTICAL ANALYSIS}

$T$-tests were used to compare child characteristics between very preterm and full-term groups. The number of skin-breaking procedures was log-transformed and shown to be normally distributed by the Komogorov-Smirnov Normality Test. Percent
Methylation of the 10 SLC6A4 CpG sites were arcsine transformed to address the issue of heteroscedasticity (Lin et al., 2008; Laird, 2010). Principal component analysis (PCA) was used to reduce the data in contrast to using the mean methylation of selected CpG sites because of significant variances. This has been used by others to examine SLC6A4 promoter methylation; the first PCA factor had the largest possible variance and was extracted to represent the overall SLC6A4 promoter methylation of the $10 \mathrm{CpG}$ sites in the dataset (Beach et al., 2010). To examine the relationship between COMT Val158Met genotypes and cumulative neonatal skin-breaking procedures (adjusted for clinical confounders), generalized linear modeling (GZLM) was used. GLZM provides an extension of general linear models and relaxes the requirement of equality or constancy of variances that is required in traditional linear models. Statistical analyses were performed using the Statistical Package for Social Sciences (SPSS) version 22 (IBM, Somers, NY); $p<0.05$ were considered statistically significant.

\section{RESULTS}

\section{PARTICIPANT CHARACTERISTICS}

Child and parent characteristics of 111 school-age children (61 born very preterm; 50 born full-term) are summarized in Table 1A. Parents of very preterm children had significantly higher self-reported depression (on the Beck Depression Inventory), compared to parents of full-term children $(p=0.02)$. Children born very preterm (in this sample that excluded children with low IQ or major brain injury and sensory-motor impairments) showed a trend toward higher Total Problems on the Child Behavior Check List completed by parents, compared to fullterms $(p=0.055)$. Neonatal characteristics of the very preterm children are shown in Table 1B. Genotype frequencies of COMT Val158Met and the 5HTTLPR variant are shown in Table 2. Due to the low frequencies of the $\mathrm{S}$ allele for $5 H T T L P R$, subjects with homozygous $S$ alleles $(S / S)$ and the L/S genotype were grouped together in all analyses. There were no significant differences in genotype frequency between very preterm and full-term children, and the distribution of 5HTTLPR and COMT Val158Met genotypes had no significant discrepancy from the Hardy-Weinberg equilibrium ( $p=0.21$ and $p=0.36$ respectively).

\section{SLC6A4 METHYLATION IN VERY PRETERM AND FULL-TERM CHILDREN}

$T$-tests with correction for multiple comparisons were used to compare the transformed methylation in the 10 SLC6A4 CpG sites (CpG 1-10) between the very preterm and full-term groups. Seven out of the 10 SLC6A4 CpG sites had significantly higher methylation (CpG 1, 3-5, 8-10) and CpG 2 had lower methylation in very preterm children compared to full-term children (Table 3A). CpG 1-5 remained significant after correction for multiple comparisons. Overall, at age 7 years, children born very preterm had higher SLC6A4 methylation compared to children born full-term.

\section{PRINCIPAL COMPONENT ANALYSIS OF SLC6A4 METHYLATION}

Principal component analysis (PCA) was used for data reduction. Three principal components had an eigenvalue $>1$, and together they accounted for $57 \%$ of the total variance in SLC6A4 methylation. Principal Component 1 (PC1) (eigenvalue = 3.2) explained 
$32 \%$ of variance, while PC2 (eigenvalue $=1.4$ ) and PC3 (eigenvalue $=1.1$ ) explained 15 and $10 \%$ respectively. Loadings of the CpG sites on the three components are shown in Table 3B. As PC1 was the predominant factor on the PCA, it was used to represent

Table 1A | Child and parent characteristics.

\begin{tabular}{|c|c|c|c|}
\hline & $\begin{array}{l}\text { Very preterm } \\
\qquad(N=61) \\
\text { mean }(S D)\end{array}$ & $\begin{array}{c}\text { Full-term } \\
(N=50) \\
\text { mean }(S D)\end{array}$ & $p$-Value \\
\hline Child age (years) & $7.7(0.3)$ & $7.9(0.9)$ & 0.090 \\
\hline Child hair cortisol (ng/ml) & $2.33(0.35)$ & $2.38(0.33)$ & 0.468 \\
\hline $\begin{array}{l}\text { Child CBCL total } \\
\text { problems T score }\end{array}$ & $51.3(10.4)$ & $47.5(10.0)$ & 0.055 \\
\hline $\begin{array}{l}\text { Child CBCL internalizing } \\
\text { behavior T score }\end{array}$ & $51.3(10.3)$ & $50.3(10.7)$ & 0.616 \\
\hline $\begin{array}{l}\text { Child CBCL externalizing } \\
\text { behavior T score }\end{array}$ & $48.7(9.6)$ & $47.9(10.3)$ & 0.694 \\
\hline Parent BDI-II & $6.9(8.0)$ & $4.0(4.6)$ & 0.020 \\
\hline Parent STAI trait anxiety & $35.4(9.7)$ & $34.2(8.3)$ & 0.471 \\
\hline
\end{tabular}

Table 1B | Neonatal characteristics of children born very preterm.

\begin{tabular}{lcc}
\hline & Mean (SD) & Range \\
\hline Male (number, \%) & $36(59)$ & \\
Gestational age at birth (weeks) & $28.2(2.1)$ & $25.0-32.9$ \\
Birth weight (g) & $1134(390)$ & $520-2265$ \\
Skin-breaks & $142(89)$ & $30-446$ \\
Cumulative morphine dose (mg) & $2.27(4.8)$ & $0-22.9$ \\
Days of mechanical ventilation & $16(17)$ & $1-58$ \\
IIIness severity day I (SNAP-II) & $15.7(11.6)$ & $0-45$ \\
Number of surgeries & $0.5(0.8)$ & $0-3$ \\
Postnatal infection (number, \%) & $27(44)$ & \\
\hline
\end{tabular}

SD, standard deviation; SNAP-II, score for neonatal acute physiology (severity of illness index).

Skin-breaks (i.e., neonatal pain-related stress) is equal to the number of skinbreaking procedures from birth to term equivalent age or hospital discharge; cumulative morphine dose is equal to daily morphine exposure adjusted for daily weight; postnatal infection is counted as the presence of a culture proven infection. the most significant aspect of methylation in SLC6A4 CpG 1-10 in the present study.

To investigate the effects of neonatal pain-related stress on child behavioral problems and SLC6A4 methylation, we examined the relationships between: (1) SLC6A4 methylation and child behavior problems; (2) number of neonatal skin-breaking procedures (adjusted for other neonatal factors) and child behavior problems; and (3) number of skin-breaking procedures (adjusted for other neonatal factors) and SLC6A4 methylation in very preterm children.

\section{SLC6A4 METHYLATION AND CHILD BEHAVIOR PROBLEMS}

To investigate factors contributing to the altered SLC6A4 methylation in very preterm children, GZLM analyses were then performed separately in very preterm and full-term children to determine the relationship with SLC6A4 methylation. Separate analyses were conducted for very preterm and full-term children since only the very preterm children were exposed to the early adversity of procedural pain, therefore we expected different relationships between the predictor variables and SLC6A4 methylation for each group. To build the group factor into the GZLM would require adding too many interaction terms. The CBCL Total Problems T score, concurrent parental depressive symptoms (BDI II) and trait anxiety (STAI), hair cortisol concentration as an index of cumulative stress level and perceived stress of the child, and 5HTTLPR genotype (LL, LS, and SS) were entered simultaneously as covariates to determine the effect on SLC6A4 methylation (Component 1 in PCA). 5HTTLPR genotype was included as a covariate because it may contribute to SLC6A4 methylation differences (Beach et al., 2014). In very preterm children, higher CBCL Total Problems score was significantly related to greater SLC6A4 methylation $\left(r^{2}=0.13 ; p=0.01\right)$ after adjusting for the other concurrent factors. For the full-term children, since the Omnibus test was not statistically significant, there was no further interpretation. Results of the GZLM are summarized in Tables $4 \mathrm{~A}, \mathbf{B}$.

COMT Val158Met was included in a separate model since this genotype may be associated with emotion and behavior regulation in children (Albaugh et al., 2010; Sheikh et al., 2013); the COMT genotype had no significant relationship with methylation $(p=0.518)$. Also, alternative models were built separately to examine whether CBCL Externalizing and Enternalizing T scores were associated with SLC6A4 methylation. Before adjusting for multiple comparisons Externalizing $(p=0.035)$ and

Table 2 | Allelic distribution of COMT and SERT genotypes.

\begin{tabular}{llcccc}
\hline & Genotype & Preterm & Full-term & Chi-squarep-value $^{\mathbf{a}}$ & Hardy-Weinberg equilibriump-value $^{\mathbf{b}}$ \\
\hline SERT 5HTTLPR & LL & 19 & 10 & 0.17 & 0.21 \\
& LS +SS & 41 & 40 & 0.78 & 0.36 \\
& GG Val/Nal & 20 & 13 & & \\
& AG Val/Met & 30 & 26 & & \\
& AA Met/Met & 10 & 9 &
\end{tabular}

a p-Values from Pearson Chi-Square tests between preterm and full-term children.

${ }^{b}$ p-Values from Hardy-Weinberg Equilibrium between allelic distributions.

L, Long allelic variant of SLC6A4 promotor; S, Short allelic; SERT, serotonin promoter gene; COMT, Catechol-O-methyltransferase. 
Table 3A | SLC6A4 percent methylation in preterm and full-term children.

\begin{tabular}{|c|c|c|c|}
\hline $\begin{array}{l}\text { SLC6A4 } \\
\text { CpG sites }\end{array}$ & $\begin{array}{c}\text { Preterm } \\
(N=61) \\
\text { mean }\left(S D^{*}\right)\end{array}$ & $\begin{array}{c}\text { Full-term } \\
(N=50) \\
\text { mean }(S D)\end{array}$ & $p$-Value ** \\
\hline $\mathrm{CpG} 1$ & $3.79(0.92)$ & $3.15(0.72)$ & $<0.0001^{\dagger}$ \\
\hline $\mathrm{CpG} 2$ & $1.60(0.66)$ & $2.00(0.44)$ & $<0.0001^{\dagger}$ \\
\hline $\mathrm{CpG} 3$ & $4.96(1.06)$ & $4.17(0.74)$ & $<0.0001^{\dagger}$ \\
\hline $\mathrm{CpG} 4$ & $1.79(0.60)$ & $1.32(0.52)$ & $0.001^{\dagger}$ \\
\hline CpG 5 & $4.06(0.87)$ & 2.69 (0.69) & $<0.0001^{\dagger}$ \\
\hline CpG 6 & $1.49(0.60)$ & $1.62(0.43)$ & 0.142 \\
\hline CpG 7 & $2.87(0.75)$ & $2.93(0.70)$ & 0.777 \\
\hline CpG 8 & $3.48(0.88)$ & $3.09(0.65)$ & 0.009 \\
\hline CpG 9 & $3.52(0.81)$ & $3.11(0.73)$ & 0.008 \\
\hline CpG 10 & 6.08 (1.43) & $5.42(1.23)$ & 0.017 \\
\hline
\end{tabular}

${ }^{*} S D$, standard deviation of $\%$ methylation.

${ }^{* *}$ p-Values of $t$-tests of the arcsine transformed SLC6A4 methylation [ $\sin ^{-1}$ $(\% \text { methylation/100 })^{1 / 2}$ ] between the preterm and full-term groups.

${ }^{\dagger}$ Significant after controlled for multiple comparisons by Bonferroni correction.

Table 3B | PCA component loadings of 10 CpG sites.

\begin{tabular}{lrcc}
\hline SLC6A4 CpG sites & Component 1 & Component 2 & Component 3 \\
\hline CpG 1 & 0.653 & -0.120 & 0.018 \\
CpG 2 & -0.107 & 0.746 & 0.247 \\
CpG 3 & 0.591 & -0.029 & 0.404 \\
CpG 4 & 0.541 & -0.466 & 0.217 \\
CpG 5 & 0.763 & -0.408 & 0.031 \\
CpG 6 & 0.031 & 0.225 & 0.801 \\
CpG 7 & 0.527 & 0.453 & -0.185 \\
CpG 8 & 0.624 & 0.142 & -0.018 \\
CpG 9 & 0.748 & 0.269 & -0.174 \\
CpG 10 & 0.546 & 0.372 & -0.278 \\
\hline
\end{tabular}

$C A$, principal component analysis.

Component 1 (eigenvalue $=3.2$ ) explained $32 \%$ of variance.

Component 2 (eigenvalue $=1.4$ ) explained $14 \%$ of variance.

Component 3 (eigenvalue $=1.1$ ) explained $11 \%$ of variance .

Internalizing $(p=0.077)$ were marginally significant, however neither was significant after adjusting for multiple comparisons of Externalizing and Internalizing scores.

\section{NEONATAL PAIN AND CHILD BEHAVIOR PROBLEMS}

To further advance our understanding of neonatal pain in relation to child behavior problems at 7 years, GZLM was used to investigate the association with CBCL Total Problems T score. Predictors were neonatal pain (cumulative skin breaking procedures from birth to term equivalent age) adjusted for clinical confounders related to prematurity (GA at birth, number of days on mechanical ventilation, illness severity on day 1 [SNAP-II], number of surgeries, presence of culture proven infection, cumulative dose of morphine), and concurrent parental depressive symptoms (BDI II) and trait anxiety (STAI), and child stress level (hair cortisol) as covariates. Greater neonatal pain (after adjustment for
Table 4A | Generalized linear modeling analysis to predict SLC6A4 methylation in very preterm children.

\begin{tabular}{|c|c|c|c|c|c|}
\hline \multirow[t]{2}{*}{ Parameter } & \multirow[t]{2}{*}{$\mathrm{B}^{\mathrm{a}}$} & \multirow[t]{2}{*}{ Std. error } & \multicolumn{2}{|c|}{$\begin{array}{c}\text { 95\% confidence } \\
\text { interval }\end{array}$} & \multirow[t]{2}{*}{$p$-Value } \\
\hline & & & Lower & Upper & \\
\hline $\begin{array}{l}\text { CBCL total problems } \\
\text { T-score }\end{array}$ & 0.042 & 0.0161 & 0.010 & 0.074 & 0.010 \\
\hline $\begin{array}{l}\text { Child hair cortisol } \\
\text { level }\end{array}$ & 0.024 & 0.4018 & -0.764 & 0.811 & 0.953 \\
\hline Parent BDI-II & -0.037 & 0.0293 & -0.094 & 0.020 & 0.207 \\
\hline $\begin{array}{l}\text { Parent STAI trait } \\
\text { anxiety score }\end{array}$ & 0.023 & 0.0216 & -0.020 & 0.065 & 0.295 \\
\hline Child 5HTTLPR LL & 0.577 & 0.3048 & -0.020 & 1.175 & 0.058 \\
\hline
\end{tabular}

Omibus test: $p=0.035$.

GZLM results showing CBCL Total Problem T-score ladjusted for concurrent stressors, hair cortisol, and 5HTTLPR genotype) associated with SLC6A4 methylation in children born very preterm.

Model: SLC6A4 methylation = CBCL Total Problem T-score + Child hair cortisol + BDI-II + STAl anxiety + 5HTTLPR genotypes.

a Unstandardized regression coefficient.

CBCL, Child Behavior Check List; BDI-II, Beck Depression Inventory 2nd edition; STAl, State Trait Anxiety Inventory; L, Long allelic variant of SLC6A4 promotor; $S$, Short allelic.

Table 4B | Generalized linear modeling analysis to predict SLC6A4 methylation in full-term children.

\begin{tabular}{|c|c|c|c|c|c|}
\hline \multirow[t]{2}{*}{ Parameter } & \multirow[t]{2}{*}{$\mathrm{B}^{\mathrm{a}}$} & \multirow[t]{2}{*}{ Std. error } & \multicolumn{2}{|c|}{$\begin{array}{c}\text { 95\% confidence } \\
\text { interval }\end{array}$} & \multirow[t]{2}{*}{$p$-Value } \\
\hline & & & Lower & Upper & \\
\hline $\begin{array}{l}\text { CBCL total problems } \\
\text { T-score }\end{array}$ & 0.040 & 0.0190 & 0.003 & 0.077 & 0.036 \\
\hline $\begin{array}{l}\text { Child hair cortisol } \\
\text { level }\end{array}$ & 0.316 & 0.4928 & -0.649 & 1.282 & 0.521 \\
\hline Parent BDI-II & 0.027 & 0.0444 & -0.060 & 0.113 & 0.550 \\
\hline $\begin{array}{l}\text { Parent STAI trait } \\
\text { anxiety score }\end{array}$ & -0.023 & 0.0272 & -0.076 & 0.031 & 0.406 \\
\hline Child 5HTTLPR LL & 0.377 & 0.3951 & -0.398 & 1.151 & 0.340 \\
\hline
\end{tabular}

Omibus test: $p=0.314$.

GZLM results showing CBCL Total Problems T-score ladjusted for concurrent stressors, hair cortisol, and 5HTTLPR genotype) associated with SLC6A4 methylation in children born very preterm.

Model: SLC6A4 methylation = CBCL Total Problems T-score + Child hair cortisol + BDI-II + STAl anxiety $+5 H T T L P R$ genotypes.

a Unstandardized regression coefficient.

CBCL, Child Behavior Check List; BDI-II, Beck Depression Inventory 2nd edition; STAI, State Trait Anxiety Inventory; L, Long allelic variant of SLC6A4 promotor; $S$, Short allelic.

all covariates) was associated with higher Total Problems score on the Child Behavior Checklist (CBCL) $\left(p=0.035, r^{2}=0.39\right)$. $5 H T T L P R$ and COMT genotypes were then added in subsequent models and were not significant $(p=0.866)$. GZLM results are summarized in Table 5. 
Table 5 | Generalized linear modeling analysis of CBCL Total Problems T scores predicted by neonatal pain-related stress.

\begin{tabular}{|c|c|c|c|c|c|}
\hline \multirow[t]{2}{*}{ Parameter } & \multirow[t]{2}{*}{$\mathrm{B}^{\mathbf{a}}$} & \multirow[t]{2}{*}{ Std. error } & \multicolumn{2}{|c|}{$\begin{array}{c}95 \% \text { confidence } \\
\text { interval }\end{array}$} & \multirow[t]{2}{*}{$p$-Value } \\
\hline & & & Lower & Upper & \\
\hline Skin-breaks & 17.99 & 8.54 & 1.25 & 34.73 & 0.035 \\
\hline Neonatal infection & 3.80 & 2.89 & -1.86 & 9.47 & 0.188 \\
\hline $\begin{array}{l}\text { Cumulative } \\
\text { morphine dose }\end{array}$ & 8.88 & 6.41 & -3.68 & 21.44 & 0.166 \\
\hline Days of ventilation & -0.04 & 0.16 & -0.35 & 0.27 & 0.779 \\
\hline SNAP-II day 1 & 0.14 & 0.12 & -0.11 & 0.38 & 0.279 \\
\hline Number of surgery & -2.24 & 1.93 & -6.03 & 1.55 & 0.246 \\
\hline Gestational age (GA) & 2.93 & 0.88 & 1.21 & 4.65 & 0.001 \\
\hline $\begin{array}{l}\text { Child hair cortisol } \\
\text { level }\end{array}$ & 2.18 & 3.36 & -4.40 & 8.76 & 0.516 \\
\hline Parent BDI-II & 0.56 & 0.25 & 0.07 & 1.06 & 0.025 \\
\hline $\begin{array}{l}\text { Parent STAI trait } \\
\text { anxiety score }\end{array}$ & -0.01 & 0.18 & -0.37 & 0.35 & 0.959 \\
\hline
\end{tabular}

GZLM results showing CBCL Total Problems T scores was predicted by neonatal pain-related stress.

Model: $C B C L$ Total Problems $T$ scores $=$ skin-breaks + Infection + morphine exposure + days of ventilation + SNAP-II + surgery + GA + Child hair cortisol + BDI-II + STAl anxiety.

a Unstandardized regression coefficient.

SNAP-II, score for neonatal acute physiology (severity of illness index).

Skin-breaks (i.e., neonatal pain-related stress) is equal to the number of skinbreaking procedures from birth to term equivalent age or hospital discharge; cumulative morphine dose is equal to daily morphine exposure adjusted for daily weight; postnatal infection is counted as the presence of a culture proven infection.

\section{EFFECT OF NEONATAL PAIN AND COMT Val158Met GENOTYPES ON SLC6A4 METHYLATION IN VERY PRETERM CHILDREN}

To test our hypothesis that neonatal pain would interact with COMT Val158Met genotype to affect SLC6A4 methylation (PC1), a GZLM model was built, in the very preterm group only, with neonatal pain (cumulative skin breaking procedures from birth to term equivalent age) and COMT Val158Met genotypes (Val/Val, Val/Met, Met/Met), and clinical confounders related to prematurity (GA, number of days on mechanical ventilation, SNAP-II day 1, number of surgeries, presence of culture proven infection, cumulative dose of morphine) as covariates. All variables and interactions were entered simultaneously in the model. GZLM results are summarized in Table 6. There was a significant interaction between COMT Val158Met genotype and neonatal pain after adjusting for clinical confounders. Greater number of skin breaking procedures (independent of these covariates) was significantly associated with lower overall SLC6A4 methylation (PC1 of PCA) in children with COMT Met/Met genotype $\left(r^{2}=0.46, p=0.001\right)$. This interaction is illustrated in Figure 1. Concurrent parental depressive symptoms (BDIII) and trait anxiety (STAI), hair cortisol level, and 5HTTLPR variants were included in a further model and none of them yielded significant results $(p=0.330,0.062,0.142$, and 0.388 respectively).
Table 6 | Generalized linear modeling analysis of SLC6A4 methylation predicted by COMT genotype and neonatal pain-related stress.

\begin{tabular}{|c|c|c|c|c|c|}
\hline \multirow[t]{2}{*}{ Parameter } & \multirow[t]{2}{*}{$\mathrm{B}^{\mathbf{a}}$} & \multirow[t]{2}{*}{ Std. error } & \multicolumn{2}{|c|}{$\begin{array}{c}95 \% \text { confidence } \\
\text { interval }\end{array}$} & \multirow[t]{2}{*}{$p$-Value } \\
\hline & & & Lower & Upper & \\
\hline $\begin{array}{l}\text { COMT Val/Nal × } \\
\text { Skin-breaks }\end{array}$ & -0.401 & 1.3908 & -3.127 & 2.325 & 0.773 \\
\hline $\begin{array}{l}\text { COMT Val/Met x } \\
\text { Skin-breaks }\end{array}$ & 1.550 & 0.9558 & -0.324 & 3.423 & 0.105 \\
\hline $\begin{array}{l}\text { COMT Met/Met x } \\
\text { Skin-breaks }\end{array}$ & -5.634 & 1.6642 & -8.896 & -2.373 & 0.001 \\
\hline COMT Val/Nal & -10.012 & 4.0286 & -17.908 & -2.116 & 0.013 \\
\hline COMT Val/Met & -14.469 & 3.4845 & -21.298 & -7.639 & 0.000 \\
\hline Neonatal infection & 0.542 & 0.3137 & -0.073 & 1.157 & 0.084 \\
\hline $\begin{array}{l}\text { Cumulative } \\
\text { morphine dose }\end{array}$ & -0.237 & 0.7364 & -1.681 & 1.206 & 0.747 \\
\hline Days of ventilation & 0.006 & 0.0153 & -0.024 & 0.036 & 0.710 \\
\hline SNAP-II day 1 & 0.016 & 0.0132 & -0.010 & 0.042 & 0.216 \\
\hline Number of surgery & -0.007 & 0.2234 & -0.445 & 0.431 & 0.976 \\
\hline Gestational age (GA) & 0.150 & 0.1057 & -0.057 & 0.357 & 0.155 \\
\hline
\end{tabular}

GZLM results showing SLC6A4 methylation was predicted by COMT genotype and neonatal pain-related stress.

Model: SLC6A4 Methylation $=($ COMT genotype $\times$ skin-breaks $)+$ Infection + COMT genotype + skin-breaks + morphine exposure + days of ventilation + SNAP-II + surgery + GA.

a Unstandardized regression coefficient.

SNAP-II, score for neonatal acute physiology (severity of illness index).

Skin-breaks (i.e., neonatal pain-related stress) is equal to the number of skinbreaking procedures from birth to term equivalent age or hospital discharge; cumulative morphine dose is equal to daily morphine exposure adjusted for daily weight; postnatal infection is counted as the presence of a culture proven infection.

\section{DISCUSSION}

This is the first study, to our knowledge, to demonstrate that children born very preterm have higher SLC6A4 promoter methylation compared to full-term children. Previous studies have shown effects of early life adversity on overall higher methylation in SLC6A4 promoter in adults who were adopted in infancy (Beach et al., 2010) and in patients with major depression (Kang et al., 2013) and bipolar disorder (Sugawara et al., 2011; Zhao et al., 2013). Moreover, our findings suggest that the stress of repeated invasive procedures that very preterm infants are exposed to while in the NICU during the first weeks to months of life may be one of the contributing factors affecting SLC6A4 methylation in the very preterm children at entry to school age. However, SLC6A4 methylation was reported to be related to various other concurrent environmental stressors (Zhao et al., 2013). Therefore, in the present study we examined and adjusted for potential effects of concurrent stressors while investigating effects of early pain-related stress on SLC6A4 methylation at age 7 years.

We found that in very preterm (but not full-term) children, higher methylation of the SLC6A4 promoter region at age 7 years was associated with overall child behavior problems, after adjusting for concurrent parent stressors, child cumulative cortisol level, 


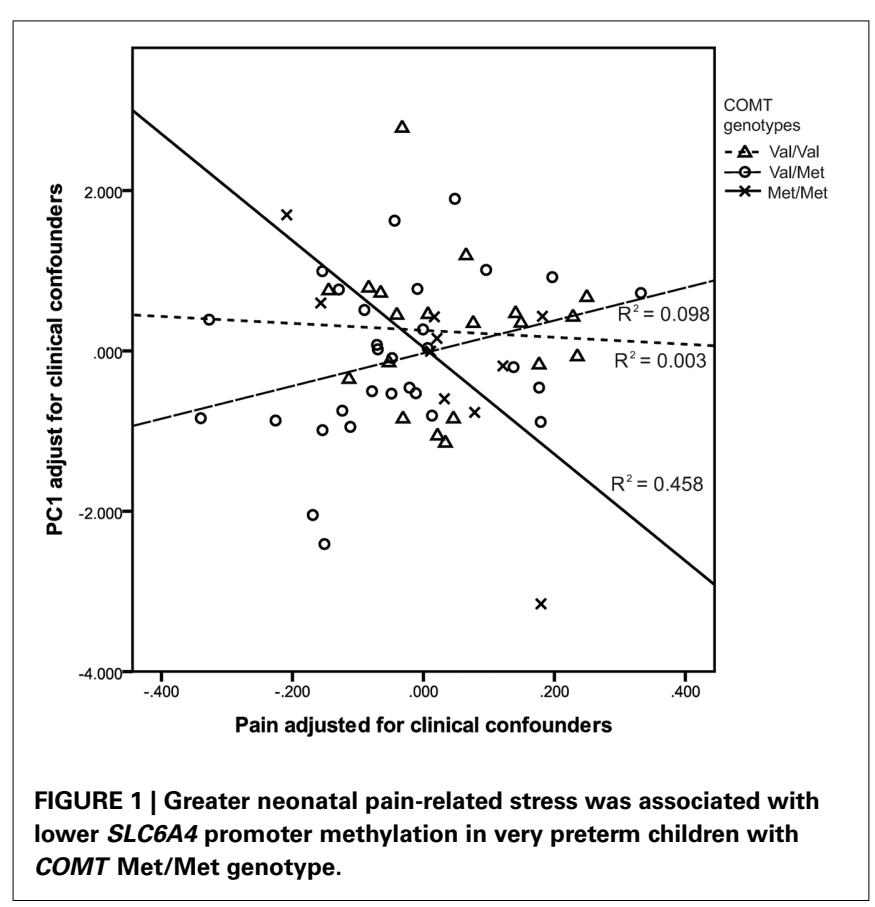

and the child 5HTTLPR genotype. The CBCL Total Problems T score was used as an index of overall emotional and behavioral problems of the child (Achenbach and Rescorla, 2000), and is associated with both concurrent and life time exposure to environmental stress (Compas et al., 1989). The children's higher order-factors of internalizing and externalizing problems were not independently found to be related to SLC6A4 methylation after adjusting for multiple comparisons. Again, the fact that the adjusted CBCL Total Problems scores were related to the overall SLC6A4 methylation only in very preterm children suggests a unique pathway to altered SLC6A4 methylation in these children. We then identified that among the neonatal factors to which only the preterm infants are exposed, greater procedural pain exposure was associated with higher child behavior problems after controlling for concurrent stressors and 5HTTLPR genotype. As has been established in the literature, lower gestational age (Loe et al., 2011) and maternal depression (Beck, 1999) both are associated with behavior problems in children. Importantly, early adversity of repeated pain-related stress early in life predicted child behavior problems above and beyond these other risk factors. In the same cohort of very preterm children, we have previously reported that greater neonatal procedural painrelated stress exposure was associated with higher internalizing behaviors at 18 months and at school age (Vinall et al., 2013b; Ranger et al., 2014), after accounting for similar clinical factors related to prematurity. In the present study we focused on exploring the relationship between neonatal pain (adjusted for clinical confounders) and SLC6A4 methylation within the very preterm group in an attempt to further advance our understanding of possible mechanisms that could explain the relationship between prematurity and child behavioral problems.

In children born very preterm we found that greater neonatal pain (adjusted for clinical confounders) was significantly associated with lower methylation, however this was only seen in those children with the COMT $158 \mathrm{Met} / \mathrm{Met}$ genotype. Previous studies in healthy adults have reported that homozygosity for the COMT 158 Met-allele was associated with greater pain sensitivity compared to individuals with the Met/Val and Val/Val genotypes (Zubieta et al., 2003). Therefore, it is possible that the COMT 158 Met/Met genotype may be more susceptible (or vulnerable) to neonatal pain. The lower SLC6A4 methylation in children with the Met/Met genotype may reflect a stress-sensitive genetic variation by which the already heightened response to early life stress/pain of these children was biologically reduced. Accordingly, it appears that COMT 158, a key dopamine-regulatory allele, may contribute to vulnerability or resilience to early life procedural stress during a period of physiological immaturity. However, in the current study, it is not possible to determine the functional effects of SLC6A4 methylation and whether increases or decreases in SLC6A4 methylation have positive or negative implications during childhood. Given that the COMT Val158Met genotype (Met/Met) differentially interacted with early exposure to neonatal pain to affect subsequent methylation of SLC6A4, we speculate that lower SLC6A4 methylation in very preterm children with the COMT $158 \mathrm{Met} / \mathrm{Met}$ genotype suggests a possible resiliency or protective mechanism for children who are exposed to early stress (Armbruster et al., 2012). One possible explanation is the increased cognitive stability linked to COMT 158 Met-allele as reported previously in infants (Markant et al., 2014), children (Diamond et al., 2004), and adults (Barnett et al., 2007). According to the tonic/phasic dopamine theory, Met allele may enhance tonic dopamine while Val enhances phasic dopamine. Phasic dopamine may be important updating working memory traces, via $\mathrm{D}_{2}$ receptors, while tonic dopamine may enhance stability of traces, via $\mathrm{D}_{1}$ receptors (Cohen et al., 2002). The sustained $\mathrm{D}_{1}$ activation (tonic dopamine) helps prevent "uncontrolled, spontaneous activation of task-irrelevant representation," (Durstewitz et al., 2000; Durstewitz and Seamans, 2002) and may function as a buffer against stressful early environment (Bilder et al., 2004).

The present study investigated the methylation status of the SLC6A4 promoter from saliva samples, since serotonergic neurons cannot be examined (Durstewitz and Seamans, 2002). Previous studies have found relationships between blood DNA methylation and mental disorders such as depression (Philibert et al., 2007; Devlin et al., 2010; Ghadirivasfi et al., 2011; Nohesara et al., 2011). Genome-wide methylation study revealed the DNA methylation levels between blood and postmortem brain tissues to be highly correlated $(r=0.90)$ (Horvath et al., 2012). Another genome-wide DNA methylation study has shown that DNA from white blood cells and saliva have $97 \%$ of genes with similar methylation patterns, and saliva samples consistently had lower methylation levels than blood samples (Thompson et al., 2013). Also, methylation of $M B-C O M T$ from DNA in postmortem brain tissues and saliva were found to be closely related (Nohesara et al., 2011). Therefore, our use of saliva methylation status is justified. In this study, the overall methylation differences between full-term and very preterm children were small but the relative percentage differences between the groups were in the same range 
as found by others in different populations (e.g., Devlin et al., 2010; Kang et al., 2013).

Our findings suggest that the highly stressful environment of repeated exposure to procedural pain-related stress that very preterm infants undergo during their stay in the NICU appears to be one of the factors contributing to the higher SLC6A4 methylation and greater behavioral problems at school-age in children born very preterm, compared to full-term. Through their prolonged hospitalization during a vulnerable period of physiological immaturity, very preterm neonates are exposed to multiple factors that appear to alter their neurodevelopmental trajectory, and teasing out specific pain-related effects is challenging. There are other factors such as prenatal parent mental health that may impact prematurity itself, as well as methylation status of offspring. Prenatal and postnatal clinical factors, treatments, and genetic variation might interact or may lead to similar end points, which makes them difficult to isolate (Grunau et al., 2013; Ranger et al., 2014). Future studies are needed to evaluate whether interventions to manage neonatal pain may ameliorate long-term epigenetic changes in very preterm infants.

\section{CONCLUSION}

This study suggests that early repeated procedural pain-related stress exposure is associated with altered methylation of the SLC6A4 promoter in children born very preterm, but only among individuals with the COMT $158 \mathrm{Met} / \mathrm{Met}$ genotype. We found a complex relationship between epigenetic modifications, COMT Val158Met genotype and early exposure to highly stressful environmental events that induce pain in children born during a critically sensitive developmental period. These findings may indicate that preterm infants with the COMT Val158Met genotype experience pain differently and as a result the long term biological impact of early pain-stress differ and could have implications for subsequent serotonin signaling. These findings begin to address mechanisms underlying pathways leading to behavioral problems or resiliency in this vulnerable population.

\section{ACKNOWLEDGMENTS}

We would like to thank Dr. Ivan Cepeda for his insights that contributed to conceptualizing this study. This research was supported by grants from the Eunice Kennedy Shriver National Institute of Child Health and Human Development (NICHD) of the National Institutes of Health (NIH) R01 HD039783 to Ruth E. Grunau, and the Canadian Institutes of Health Research (CIHR) MOP86489 to Ruth E. Grunau. Ruth E. Grunau is supported by a Senior Scientist Award from the Child and Family Research Institute. Cecil M. Y. Chau and is supported by a graduate stipend from the Pain in Child Health (PICH) CIHR Strategic Training Program. Manon Ranger is supported by CIHR and Health Research Funds of Quebec Post-doctoral Fellowships. Tim F. Oberlander is the R. Howard Webster Professor in Early Child Development (UBC, School of Population and Public Health).

\section{REFERENCES}

Aarnoudse-Moens, C. S., Weisglas-Kuperus, N., van Goudoever, J. B., and Oosterlaan, J. (2009). Meta-analysis of neurobehavioral outcomes in very preterm and/or very low birth weight children. Pediatrics $124,717-728$. doi: 10.1542/peds.2008-2816

Aberg, E., Fandino-Losada, A., Sjoholm, L. K., Forsell, Y., and Lavebratt, C. (2011). The functional Val158Met polymorphism in catechol-O-methyltransferase (COMT) is associated with depression and motivation in men from a Swedish population-based study. J. Affect. Disord. 129, 158-166. doi: 10.1016/j.jad.2010.08.009

Achenbach, T. M., and Rescorla, L. A. (2000). Manual for ASEBA Preschool Forms and Profiles. Burlington, VT: University of Vermont, Research Center for Children, Youth, and Families.

Albaugh, M. D., Harder, V. S., Althoff, R. R., Rettew, D. C., Ehli, E. A., LengyelNelson, T., et al. (2010). COMT Val158Met genotype as a risk factor for problem behaviors in youth. J. Am. Acad. Child Adolesc. Psychiatry 49, 841-849. doi: 10.1016/j.jaac.2010.05.015

Armbruster, D., Mueller, A., Strobel, A., Lesch, K. P., Brocke, B., and Kirschbaum, C. (2012). Children under stress-COMT genotype and stressful life events predict cortisol increase in an acute social stress paradigm. Int. J. Neuropsychopharmacol. 15, 1229-1239. doi: 10.1017/S1461145711 001763

Ascher, J. A., Cole, J. O., Colin, J. N., Feighner, J. P., Ferris, R. M., Fibiger, H. C., et al. (1995). Bupropion: a review of its mechanism of antidepressant activity. J. Clin. Psychiatry 56, 395-401.

Bagot, R. C., Zhang, T. Y., Wen, X., Nguyen, T. T., Nguyen, H. B., Diorio, J., et al. (2012). Variations in postnatal maternal care and the epigenetic regulation of metabotropic glutamate receptor 1 expression and hippocampal function in the rat. Proc. Natl. Acad. Sci. U.S.A. 109, 17200-17207. doi: 10.1073/pnas.1204599109

Barnett, J. H., Jones, P. B., Robbins, T. W., and Muller, U. (2007). Effects of the catechol-O-methyltransferase Val158Met polymorphism on executive function: a meta-analysis of the Wisconsin Card Sort Test in schizophrenia and healthy controls. Mol. Psychiatry 12, 502-509. doi: 10.1038/sj.mp.4001973

Beach, S. R., Brody, G. H., Todorov, A. A., Gunter, T. D., and Philibert, R. A. (2010). Methylation at SLC6A4 is linked to family history of child abuse: an examination of the Iowa Adoptee sample. Am. J. Med. Genet. B Neuropsychiatr. Genet. 153B, 710-713. doi: 10.1002/ajmg.b.31028

Beach, S. R., Dogan, M. V., Brody, G. H., and Philibert, R. A. (2014). Differential impact of cumulative SES risk on methylation of protein-protein interaction pathways as a function of SLC6A4 genetic variation in African American young adults. Biol Psychol. 96, 28-34. doi: 10.1016/j.biopsycho.2013.10.006

Beck, A. T., Ward, C. H., Mendelson, M., Mock, J., and Erbaugh, J. (1961). An inventory for measuring depression. Arch. Gen. Psychiatry 4, 561-571. doi: 10.1001/archpsyc.1961.01710120031004

Beck, C. T. (1999). Maternal depression and child behaviour problems: a meta-analysis. J. Adv. Nurs. 29, 623-629. doi: 10.1046/j.1365-2648.1999. 00943.x

Benes, F. M., Taylor, J. B., and Cunningham, M. C. (2000). Convergence and plasticity of monoaminergic systems in the medial prefrontal cortex during the postnatal period: implications for the development of psychopathology. Cereb. Cortex 10, 1014-1027. doi: 10.1093/cercor/10.10.1014

Bhutta, A. T., Cleves, M. A., Casey, P. H., Cradock, M. M., and Anand, KJS. (2002). Cognitive and behavioral outcomes of school-aged children who were born preterm: a meta-analysis. JAMA 288, 728-737. doi: 10.1001/jama. 288.6.728

Bialecka, M., Kurzawski, M., Klodowska-Duda, G., Opala, G., Tan, E. K., and Drozdzik, M. (2008). The association of functional catechol-Omethyltransferase haplotypes with risk of Parkinson's disease, levodopa treatment response, and complications. Pharmacogenet. Genomics 18, 815-821. doi: 10.1097/FPC.0b013e328306c2f2

Bilder, R. M., Volavka, J., Lachman, H. M., and Grace, A. A. (2004). The catecholO-methyltransferase polymorphism: relations to the tonic-phasic dopamine hypothesis and neuropsychiatric phenotypes. Neuropsychopharmacology 29, 1943-1961. doi: 10.1038/sj.npp.1300542

Blasi, G., Mattay, V. S., Bertolino, A., Elvevag, B., Callicott, J. H., Das, S., et al. (2005). Effect of catechol-O-methyltransferase val158met genotype on attentional control. J. Neurosci. 25, 5038-5045. doi: 10.1523/JNEUROSCI.047605.2005

Brummelte, S., Grunau, R. E., Chau, V., Poskitt, K. J., Brant, R., Vinall, J., et al. (2012). Procedural pain and brain development in premature newborns. Ann. Neurol. 71, 385-396. doi: 10.1002/ana.22267 
Caspi, A., Sugden, K., Moffitt, T. E., Taylor, A., Craig, I. W., Harrington, H., et al. (2003). Influence of life stress on depression: moderation by a polymorphism in the 5-HTT gene. Science 301, 386-389. doi: 10.1126/science. 1083968

Chen, J., Lipska, B. K., Halim, N., Ma, Q. D., Matsumoto, M., Melhem, S., et al. (2004). Functional analysis of genetic variation in catechol-Omethyltransferase (COMT): effects on mRNA, protein, and enzyme activity in postmortem human brain. Am. J. Hum. Genet. 75, 807-821. doi: 10.1086/ 425589

Cohen, J. D., Braver, T. S., and Brown, J. W. (2002). Computational perspectives on dopamine function in prefrontal cortex. Curr. Opin. Neurobiol. 12, 223-229. doi: 10.1016/S0959-4388(02)00314-8

Compas, B. E., Howell, D. C., Phares, V., Williams, R. A., and Giunta, C. T. (1989) Risk factors for emotional/behavioral problems in young adolescents: a prospective analysis of adolescent and parental stress and symptoms. J. Consult. Clin. Psychol. 57, 732-740. doi: 10.1037/0022-006X.57.6.732

Devlin, A. M., Brain, U., Austin, J., and Oberlander, T. F. (2010). Prenatal exposure to maternal depressed mood and the MTHFR C677T variant affect SLC6A4 methylation in infants at birth. PLoS ONE. 5:e12201. doi: 10.1371/journal.pone.0012201

Diamond, A., Briand, L., Fossella, J., and Gehlbach, L. (2004). Genetic and neurochemical modulation of prefrontal cognitive functions in children. Am. J. Psychiatry 161, 125-132. doi: 10.1176/appi.ajp.161.1.125

Doesburg, S. M., Chau, C. M., Cheung, T. P., Moiseev, A., Ribary, U., Herdman, A. T., et al. (2013). Neonatal pain-related stress, functional cortical activity and visual-perceptual abilities in school-age children born at extremely low gestational age. Pain 154, 1946-1952. doi: 10.1016/j.pain.2013. 04.009

Dumontheil, I., Roggeman, C., Ziermans, T., Peyrard-Janvid, M., Matsson, H., Kere, J., et al. (2011). Influence of the COMT genotype on working memory and brain activity changes during development. Biol. Psychiatry 70, 222-229. doi: 10.1016/j.biopsych.2011.02.027

Dupont, J. M., Tost, J., Jammes, H., and Gut, I. G. (2004). De novo quantitative bisulfite sequencing using the pyrosequencing technology. Anal. Biochem. 333, 119-127. doi: 10.1016/j.ab.2004.05.007

Durstewitz, D., and Seamans, J. K. (2002). The computational role of dopamine D1 receptors in working memory. Neural Netw. 15, 561-572. doi: 10.1016/S08936080(02)00049-7

Durstewitz, D., Seamans, J. K., and Sejnowski, T. J. (2000). Dopamine-mediated stabilization of delay-period activity in a network model of prefrontal cortex. J. Neurophysiol. 83, 1733-1750.

Enoch, M. A., Xu, K., Ferro, E., Harris, C. R., and Goldman, D. (2003). Genetic origins of anxiety in women: a role for a functional catechol-O-methyltransferase polymorphism. Psychiatr. Genet. 13, 33-41. doi: 10.1097/00041444-20030300000006

Fan, J. B., Zhang, C. S., Gu, N. F., Li, X. W., Sun, W. W., Wang, H. Y., et al. (2005). Catechol-O-methyltransferase gene Val/Met functional polymorphism and risk of schizophrenia: a large-scale association study plus meta-analysis. Biol. Psychiatry 57, 139-144. doi: 10.1016/j.biopsych.2004. 10.018

Garris, P. A., and Wightman, R. M. (1994). Different kinetics govern dopaminergic transmission in the amygdala, prefrontal cortex, and striatum: an in vivo voltammetric study. J. Neurosci. 14, 442-450.

Gatewood-Colwell, G., Kaczmarek, M., and Ames, M. H. (1989). Reliability and validity of the Beck Depression Inventory for a white and MexicanAmerican gerontic population. Psychol. Rep. 65(3 Pt 2), 1163-1166. doi: 10.2466/pr0.1989.65.3f.1163

Ghadirivasfi, M., Nohesara, S., Ahmadkhaniha, H. R., Eskandari, M. R., Mostafavi, S., Thiagalingam, S., et al. (2011). Hypomethylation of the serotonin receptor type-2A Gene (HTR2A) at T102C polymorphic site in DNA derived from the saliva of patients with schizophrenia and bipolar disorder. Am. J. Med. Genet. B Neuropsychiatr. Genet. 156B, 536-545. doi: 10.1002/ajmg.b.31192

Gray, R. F., Indurkhya, A., and McCormick, M. C. (2004). Prevalence, stability, and predictors of clinically significant behavior problems in low birth weight children at 3,5 , and 8 years of age. Pediatrics 114, 736-743. doi: 10.1542/peds.2003-1150-L

Grunau, R. E., Cepeda, I. L., Chau, C. M. Y., Brummelte, S., Weinberg, J., Lavoie, P., et al. (2013). Neonatal pain-related stress and NFKBIA genotype are associated with altered cortisol levels in preterm boys at school age. PLoS ONE 8:e73926. doi: 10.1371/journal.pone.0073926

Grunau, R. E., Haley, D. W., Whitfield, M. F., Weinberg, J., Yu, W., and Thiessen, P. (2007). Altered basal cortisol levels at 3, 6, 8 and 18 months in infants born at extremely low gestational age. J. Pediatr. 150, 151-156. doi: 10.1016/j.jpeds.2006.10.053

Grunau, R. E., Weinberg, J., and Whitfield, M. F. (2004). Neonatal procedural pain and preterm infant cortisol response to novelty at 8 months. Pediatrics 114, e77-e84. doi: 10.1542/peds.114.1.e77

Grunau, R. E., Whitfield, M. F., Petrie-Thomas, J., Synnes, A. R., Cepeda, I. L., Keidar, A., et al. (2009). Neonatal pain, parenting stress and interaction, in relation to cognitive and motor development at 8 and 18 months in preterm infants. Pain 143, 138-146. doi: 10.1016/j.pain.2009. 02.014

Hanley, G. E., and Oberlander, T. F. (2012). Neurodevelopmental outcomes following prenatal exposure to serotonin reuptake inhibitor antidepressants: a "social teratogen" or moderator of developmental risk? Birth Defects Res. A Clin. Mol. Teratol. 94, 651-659. doi: 10.1002/bdra. 23032

Heils, A., Teufel, A., Petri, S., Stober, G., Riederer, P., Bengel, D., et al. (1996). Allelic variation of human serotonin transporter gene expression. J. Neurochem. 66, 2621-2624. doi: 10.1046/j.1471-4159.1996.6606 2621.x

Homberg, J. R., and Lesch, K. P. (2011). Looking on the bright side of serotonin transporter gene variation. Biol. Psychiatry 69, 513-519. doi: 10.1016/j.biopsych.2010.09.024

Homberg, J. R., Schubert, D., and Gaspar, P. (2010). New perspectives on the neurodevelopmental effects of SSRIs. Trends Pharmacol. Sci. 31, 60-65. doi: 10.1016/j.tips.2009.11.003

Horvath, S., Zhang, Y., Langfelder, P., Kahn, R. S., Boks, M. P., van Eijk, K., et al. (2012). Aging effects on DNA methylation modules in human brain and blood tissue. Genome Biol. 13:R97. doi: 10.1186/gb-2012-13-10-r97

Kang, H. J., Kim, J. M., Stewart, R., Kim, S. Y., Bae, K. Y., Kim, S. W., et al. (2013). Association of SLC6A4 methylation with early adversity, characteristics and outcomes in depression. Prog. Neuropsychopharmacol. Biol. Psychiatry 44, 23-28. doi: 10.1016/j.pnpbp.2013.01.006

Karoum, F., Chrapusta, S. J., and Egan, M. F. (1994). 3-Methoxytyramine is the major metabolite of released dopamine in the rat frontal cortex: reassessment of the effects of antipsychotics on the dynamics of dopamine release and metabolism in the frontal cortex, nucleus accumbens, and striatum by a simple two pool model. J. Neurochem. 63, 972-979. doi: 10.1046/j.14714159.1994.63030972.x

Karsten, C. A., and Baram, T. Z. (2013). How does a neuron "know" to modulate its epigenetic machinery in response to early-life environment/experience? Front. Psychiatry 4:89. doi: 10.3389/fpsyt.2013.00089

Kuzelova, H., Ptacek, R., and Macek, M. (2010). The serotonin transporter gene (5-HTT) variant and psychiatric disorders: review of current literature. Neuro Endocrinol. Lett. 31, 4-10.

Laird, P. W. (2010). Principles and challenges of genomewide DNA methylation analysis. Nat. Rev. Genet. 11, 191-203. doi: 10.1038/ nrg2732

Lesch, K. P. (2007). Linking emotion to the social brain. The role of the serotonin transporter in human social behaviour. EMBO Rep. 8, Spec No:S24-9. doi: 10.1038/sj.embor.7401008

Lin, S. M., Du, P., Huber, W., and Kibbe, W. A. (2008). Model-based variancestabilizing transformation for Illumina microarray data. Nucleic Acids Res. 36, ell. doi: 10.1093/nar/gkm1075

Loe, I. M., Lee, E. S., Luna, B., and Feldman, H. M. (2011). Behavior problems of 9-16 year old preterm children: biological, sociodemographic, and intellectual contributions. Early Hum. Dev. 87, 247-252. doi: 10.1016/j.earlhumdev.2011.01.023

Lotta, T., Vidgren, J., Tilgmann, C., Ulmanen, I., Melen, K., Julkunen, I., et al. (1995). Kinetics of human soluble and membrane-bound catechol Omethyltransferase: a revised mechanism and description of the thermolabile variant of the enzyme. Biochemistry 34, 4202-4210. doi: 10.1021/bi000 $13 \mathrm{a} 008$

Lucki, I. (1998). The spectrum of behaviors influenced by serotonin. Biol. Psychiatry 44, 151-162. doi: 10.1016/S0006-3223(98)00139-5 
Markant, J., Cicchetti, D., Hetzel, S., and Thomas, K. M. (2014). Contributions of COMT Val Met to cognitive stability and flexibility in infancy. Dev. Sci. 17, 396-411. doi: 10.1111/desc. 12128

McGowan, P. O., Sasaki, A., D’Alessio, A. C., Dymov, S., Labonte, B., Szyf, M., et al. (2009). Epigenetic regulation of the glucocorticoid receptor in human brain associates with childhood abuse. Nat. Neurosci. 12, 342-348. doi: $10.1038 / \mathrm{nn} .2270$

Meaney, M. J. (2010). Epigenetics and the biological definition of gene $\mathrm{x}$ environment interactions. Child Dev. 81, 41-79. doi: 10.1111/j.1467-8624.2009. 01381.x

Miller, G. E., Chen, E., and Parker, K. J. (2011). Psychological stress in childhood and susceptibility to the chronic diseases of aging: moving toward a model of behavioral and biological mechanisms. Psychol. Bull. 137, 959-997. doi: $10.1037 / \mathrm{a} 0024768$

Nohesara, S., Ghadirivasfi, M., Mostafavi, S., Eskandari, M. R., Ahmadkhaniha, H., Thiagalingam, S., et al. (2011). DNA hypomethylation of MB-COMT promoter in the DNA derived from saliva in schizophrenia and bipolar disorder. J. Psychiatr. Res. 45, 1432-1438. doi: 10.1016/j.jpsychires.2011. 06.013

Oberlander, T. F., Papsdorf, M., Brain, U. M., Misri, S., Ross, C., and Grunau, R. E. (2010). Prenatal effects of selective serotonin reuptake inhibitor antidepressants, serotonin transporter promoter genotype (SLC6A4), and maternal mood on child behavior at 3 years of age. Arch. Pediatr. Adolesc. Med. 164, 444-451. doi: 10.1001/archpediatrics.2010.51

Oberlander, T. F., Weinberg, J., Papsdorf, M., Grunau, R. E., Misri, S., and Devlin, A. M. (2008). Prenatal exposure to maternal depression, neonatal methylation of human glucocorticoid receptor gene (NR3C1) and infant cortisol stress responses. Epigenetics 3, 97-106. doi: 10.4161/epi. 3.2.6034

Olivier, J. D., Blom, T., Arentsen, T., and Homberg, J. R. (2011). The agedependent effects of selective serotonin reuptake inhibitors in humans and rodents: a review. Prog. Neuropsychopharmacol. Biol. Psychiatry 35, 1400-1408. doi: 10.1016/j.pnpbp.2010.09.013

Olsson, C. A., Byrnes, G. B., Anney, R. J., Collins, V., Hemphill, S. A., Williamson, R., et al. (2007). COMT Val(158)Met and 5HTTLPR functional loci interact to predict persistence of anxiety across adolescence: results from the Victorian Adolescent Health Cohort Study. Genes Brain Behav. 6, 647-652. doi: 10.1111/j.1601-183X.2007.00313.x

Philibert, R., Madan, A., Andersen, A., Cadoret, R., Packer, H., and Sandhu, H. (2007). Serotonin transporter mRNA levels are associated with the methylation of an upstream CpG island. Am. J. Med. Genet. B Neuropsychiatr. Genet. 144B, 101-105. doi: 10.1002/ajmg.b.30414

Philibert, R. A., Sandhu, H., Hollenbeck, N., Gunter, T., Adams, W., and Madan, A. (2008). The relationship of 5HTT (SLC6A4) methylation and genotype on mRNA expression and liability to major depression and alcohol dependence in subjects from the Iowa Adoption Studies. Am. J. Med. Genet. B Neuropsychiatr. Genet. 147B, 543-549. doi: 10.1002/ajmg.b.30657

Radua, J., El-Hage, W., Monte, G. C., Gohier, B., Tropeano, M., Phillips, M. L., et al. (2014). COMT Val158Met x SLC6A4 5-HTTLPR interaction impacts on gray matter volume of regions supporting emotion processing. Soc. Cogn. Affect. Neurosci. 9, 1232-1238. doi: 10.1093/scan/nst089

Ranger, M., Chau, C. M., Garg, A., Woodward, T. S., Beg, M. F., Bjornson, B., et al. (2013). Neonatal pain-related stress predicts cortical thickness at age 7 years in children born very preterm. PLoS ONE 8:e76702. doi: 10.1371/journal.pone.0076702

Ranger, M., Synnes, A. R., Vinall, J., and Grunau, R. E. (2014). Internalizing behaviours in school-age children born very preterm are predicted by neonatal pain and morphine exposure. Eur. J. Pain 18, 844-852. doi: 10.1002/j.15322149.2013.00431.x

Richardson, D. K., Corcoran, J. D., Escobar, G. J., and Lee, S. K. (2001). SNAP-II and SNAPPE-II: simplified newborn illness severity and mortality risk scores. J. Pediatr. 138, 92-100. doi: 10.1067/mpd.2001.109608

Rutter, M., Moffitt, T. E., and Caspi, A. (2006). Gene-environment interplay and psychopathology: multiple varieties but real effects. J. Child Psychol. Psychiatry 47, 226-261. doi: 10.1111/j.1469-7610.2005.01557.x

Sasaki-Adams, D. M., and Kelley, A. E. (2001). Serotonin-dopamine interactions in the control of conditioned reinforcement and motor behavior Neuropsychopharmacology 25, 440-452. doi: 10.1016/S0893-133X(01)00240-8
Sauve, B., Koren, G., Walsh, G., Tokmakejian, S., and Van Uum, S. H. (2007). Measurement of cortisol in human hair as a biomarker of systemic exposure. Clin. Invest. Med. 30, E183-E191.

Serretti, A., Kato, M., De Ronchi, D., and Kinoshita, T. (2007). Meta-analysis of serotonin transporter gene promoter polymorphism (5-HTTLPR) association with selective serotonin reuptake inhibitor efficacy in depressed patients. Mol. Psychiatry 12, 247-257. doi: 10.1038/sj.mp.4001926

Sheikh, H. I., Kryski, K. R., Smith, H. J., Dougherty, L. R., Klein, D. N., Bufferd, S. J., et al. (2013). Catechol-O-methyltransferase gene val158met polymorphism and depressive symptoms during early childhood. Am. J. Med. Genet. B Neuropsychiatr. Genet. 162B, 245-252. doi: 10.1002/ajmg.b. 32141

Simpson, K. L., Weaver, K. J., de Villers-Sidani, E., Lu, J. Y., Cai, Z., Pang, Y., et al. (2011). Perinatal antidepressant exposure alters cortical network function in rodents. Proc. Natl. Acad. Sci. U.S.A. 108, 18465-18470. doi: $10.1073 /$ pnas. 1109353108

Spielberger, C. D., Gorsuch, R. L., Lushene, R., Vagg, P. R., and Jacobs, G. A. (1983). Manual for the State-Trait Anxiety Inventory. Palo Alto, CA: Consulting Psychologists Press.

Sugawara, H., Iwamoto, K., Bundo, M., Ueda, J., Miyauchi, T., Komori, A., et al. (2011). Hypermethylation of serotonin transporter gene in bipolar disorder detected by epigenome analysis of discordant monozygotic twins. Transl. Psychiatry 1:e24. doi: 10.1038/tp.2011.26

Thompson, T. M., Sharfi, D., Lee, M., Yrigollen, C. M., Naumova, O. Y., and Grigorenko, E. L. (2013). Comparison of whole-genome DNA methylation patterns in whole blood, saliva, and lymphoblastoid cell lines. Behav. Genet. 43, 168-176. doi: 10.1007/s10519-012-9579-1

Tu, M. T., Grunau, R. E., Petrie-Thomas, J., Haley, D. W., Weinberg, J., and Whitfield, M. F. (2007). Maternal stress and behavior modulate relationships between neonatal stress, attention, and basal cortisol at 8 months in preterm infants. Dev. Psychobiol. 49, 150-164. doi: 10.1002/dev. 20204

Vaghri, Z., Guhn, M., Weinberg, J., Grunau, R. E., Yu, W., and Hertzman, C. (2013). Hair cortisol reflects socio-economic factors and hair zinc in preschoolers. Psychoneuroendocrinology 38, 331-340. doi: 10.1016/j.psyneuen.2012. 06.009

Vinall, J., Grunau, R. E., Brant, R., Chau, V., Poskitt, K. J., Synnes, A. R., et al. (2013a). Slower postnatal growth is associated with delayed cerebral cortical maturation in preterm newborns. Sci. Transl. Med. 5, 168ra8. doi: 10.1126/scitranslmed.3004666

Vinall, J., Miller, S., Synnes, A., and Grunau, R. (2013b). Parent behaviors moderate the relationship between neonatal pain and internalizing behaviors at 18 months corrected age in children born very prematurely. Pain 154, 1831-1839. doi: 10.1016/j.pain.2013.05.050

Wechsler, D. (2003). Wechsler Intelligence Scales for Children, 4th Edn. San Antonio, TX: Psychological Corporation.

Weikum, W. M., Brain, U., Chau, C. M., Grunau, R. E., Boyce, W. T., Diamond, A., et al. (2013). Prenatal serotonin reuptake inhibitor (SRI) antidepressant exposure and serotonin transporter promoter genotype (SLC6A4) influence executive functions at 6 years of age. Front. Cell. Neurosci. 7:180. doi: $10.3389 /$ fncel.2013.00180

Zhao, J., Goldberg, J., Bremner, J. D., and Vaccarino, V. (2013). Association between promoter methylation of serotonin transporter gene and depressive symptoms: a monozygotic twin study. Psychosom. Med. 75, 523-529. doi: 10.1097/PSY.0b013e3182924cf4

Zubieta, J. K., Heitzeg, M. M., Smith, Y. R., Bueller, J. A., Xu, K., Xu, Y. et al. (2003). COMT val158met genotype affects mu-opioid neurotransmitter responses to a pain stressor. Science 299, 1240-1243. doi: 10.1126/science. 1078546

Zwicker, J. G., Grunau, R. E., Chau, V., Synnes, A., Poskitt, K. J., Brant, R., et al. (eds.). (2013b). Neonatal Pain is Associated with Altered Corticospinal Tract Development in Premature Newborns and Gross Motor Outcomes at 18 Months. Platform Presentation. San Francisco, CA: Pediatric Academic Societies.

Zwicker, J. G., Yoon, S. W., Mackay, M., Petrie-Thomas, J., Rogers, M., and Synnes, A. R. (2013a). Perinatal and neonatal predictors of developmental coordination disorder in very low birthweight children. Arch. Dis. Child. 98, 118-122. doi: 10.1136/archdischild-2012-302268 
Conflict of Interest Statement: The authors are responsible for the reported research. We have participated in the concept and design, acquisition of the data, analysis and interpretation of data, as well as drafting and/or revising the manuscript. None of us has any affiliation, financial agreement, or other involvement that would place us in conflict of interest with this manuscript. The authors declare that the research was conducted in the absence of any commercial or financial relationships that could be construed as a potential conflict of interest.

Received: 22 August 2014; accepted: 11 November 2014; published online: 02 December 2014.
Citation: Chau CMY, Ranger M, Sulistyoningrum D, Devlin AM, Oberlander TF and Grunau RE (2014) Neonatal pain and COMT Val158Met genotype in relation to serotonin transporter (SLC6A4) promoter methylation in very preterm children at school age. Front. Behav. Neurosci. 8:409. doi: 10.3389/fnbeh.2014.00409

This article was submitted to the journal Frontiers in Behavioral Neuroscience.

Copyright (C) 2014 Chau, Ranger, Sulistyoningrum, Devlin, Oberlander and Grunau. This is an open-access article distributed under the terms of the Creative Commons Attribution License (CC BY). The use, distribution or reproduction in other forums is permitted, provided the original author(s) or licensor are credited and that the original publication in this journal is cited, in accordance with accepted academic practice. No use, distribution or reproduction is permitted which does not comply with these terms. 